5 Hough D, Lindenmayer JP, Gopal S, Melkote R, Lim P, Herben V, et al. Safety and tolerability of deltoid and gluteal injections of paliperidone palmitate in schizophrenia. Prog Neuropsychopharmacol Biol Psychiatry 2009; 33: 1022-31.

Paraskevi Nikolaidou, email: paraskevi.n@nsft.nhs.uk, and Marinos Chatzopoulos are core trainees, Norfolk and Suffolk NHS Foundation Trust, Dionysis Seretis is a research associate, the Open University, and Albert Michael is a consultant psychiatrist, Norfolk and Suffolk NHS Foundation Trust, Wedgwood House, Bury-St-Edmunds, UK.

doi: $10.1192 / \mathrm{pb} .37 .9 .308 \mathrm{a}$

\section{All future psychiatrists should be neuropsychiatrists}

Conn \& Cavanna ${ }^{1}$ discuss a meeting point for neurology and psychiatry. This is very important. My own view is that all future psychiatrists should be neuropsychiatrists.

\section{Books received}

Tackling Health Anxiety: A CBT Handbook

Helen Tyrer

RCPsych Publications, 2013, E18.00 pb, 150 pp. ISBN: 9781908020901

Cognitive Behavioural Prevention of Suicide in Psychosis:

A Treatment Manual

Nicholas Tarrier, Patricia Gooding, Daniel Pratt, James Kelly, Yvonne Awenat

$\&$ Janet Maxwell

Routledge, 2013, £27.99 pb, 264 pp. ISBN: 9780415658706

Drugs in Psychiatry (2nd edn)

Basant K. Puri

Oxford University Press, 2013, £29.99 pb, 240 pp. ISBN: 9780199670444

Rating Scales in Mental Health (3rd edn)

Martha Sajatovic \& Luis F. Ramirez

Johns Hopkins University Press, 2012, £31.00 pb, 512 pp.

ISBN: 9781421406664

The Clinical Handbook of Biofeedback: A Step-by-Step Guide for Training and Practice with Mindfulness

Inna Z. Khazan

Wiley-Blackwell, 2013, E34.99 pb, 354 pp.

ISBN: 9781119993711

My Nine Lives: A Psychotherapist's Journey from Victim to Survivor

Jane Leigh

AuthorHouse, 2012, £12.95 pb, 258 pp.

ISBN: 9781477239650

Forensic Music Therapy: A Treatment for Men and Women in Secure Hospital Settings

Stella Compton Dickinson, Helen Odell-Miller \& John Adlam (eds)

Jessica Kingsley Publishers, 2013, £24.99 pb, 256 pp.

ISBN: 9781849052528

Psychiatry at a Glance (5th edn)

Cornelius Katona, Claudia Cooper \& Mary Robertson

Wiley-Blackwell, 2012, £23.99 pb, 128 pp. ISBN: 9780470658918

Depression (2nd edn)

Raymond W. Lam

Oxford University Press, 2012, E12.00 pb, 144 pp. ISBN: 9780199692736

Clinical Psychometrics

Per Bech

Wiley-Blackwell, 2012, £27.50 pb, 200 pp. ISBN: 9781118329788

Depression and Anxiety in Later Life: What Everyone Needs to Know

Mark D. Miller \& Charles F. Reynolds III

Johns Hopkins Press, 2012, £10.50 pb, 224 pp. ISBN: 9781421406305

The Therapeutic Milieu Under Fire: Security and Insecurity in Forensic Mental Health

John Adlam, Anne Aiyebusi, Pam Kleinot, Anna Motz

$\&$ Christopher Scanlon (eds)

Jessica Kingsley Publishers, 2012, £29.99 pb, 240 pp.

ISBN: 9781849052580

Developmental Assessment of the School-Aged Child

with Developmental Disabilities: A Clinician's Guide

M. S. Thambirajah

Jessica Kingsley Publishers, 2011, £40.00 pb, 336 pp. ISBN: 9781849051811
Psychological therapies should be provided by nonpsychiatrists. The role of the neuropsychiatrist would be largely diagnostic and implementation of medical treatment (mainly psychopharmacology). This is the only way that makes sense of the medical degree in the first place.

New dual postgraduate training programmes in neurology and psychiatry should be instituted. The financial cost of a psychiatrist providing psychotherapy is prohibitive in the current climate.

1 Conn R, Cavanna AE. A meeting point for neurology and psychiatry? Psychiatrist 2013; 37: 147-8.

Michael Fitzgerald, Psychiatrist, Trinity College Dublin, Ireland, email: prof.m.fitzgerald@gmail.com

doi: 10.1192/pb.37.9.309

Managing the Side Effects of Psychotropic Medications Joseph F. Goldberg \& Carrie L. Ernst

American Psychiatric Publishing, 2012, $£ 43.00$ pb, 532 pp. ISBN: 9781585624027

Intersectionality, Sexuality and Psychological Therapies:

Working with Lesbian, Gay and Bisexual Diversity

Roshan das Nair \& Catherine Butler (eds)

Wiley-Blackwell, 2012, E34.99 pb, 298 pp. ISBN: 9780470974995

The Art and Science of Brief Psychotherapies: An Illustrated Guide (2nd edn)

Mantosh J. Dewan, Brett N. Steenbarger \& Roger P. Greenberg (eds)

American Psychiatric Publishing, 2012, $£ 52.00$ pb, 372 pp.

ISBN: 9781585623969

Clinician's Handbook for Obsessive Compulsive Disorder:

Inference-Based Therapy

Kieron O'Connor \& Frederick Aardema

Wiley-Blackwell, 2011, £29.99 pb, 352 pp. ISBN: 9780470684108

Clinical Manual for Treatment of Schizophrenia

John Lauriello \& Stefano Pallanti (eds)

American Psychiatric Publishing, 2012, £52.00 pb, 523 pp.

ISBN: 9781585623945

From the Couch to the Lab: Trends in Psychodynamic Neuroscience

Aikaterini Fotopoulou, Donald Pfaff \& Martin A. Conway (eds)

Oxford University Press, 2012, E55.00 hb, 506 pp. ISBN: 9780199600526

Clinical Manual of Alzheimer Disease and Other Dementias

Myron F. Weiner \& Anne M. Lipton (eds)

American Psychiatric Publishing, 2012, $£ 46.00$ pb, 470 pp.

ISBN: 9781585624225

Textbook of Psychoanalysis (2nd edn)

Glen O. Gabbard, Bonnie E. Litowitz \& Paul Williams (eds)

American Psychiatric Publishing, 2012, $£ 82.00$ hb, 636 pp.

ISBN: 9781585624102

Cognitive Therapy for Addiction: Motivation and Change

Frank Ryan

Wiley-Blackwell, 2013, £32.99 pb, 230 pp.

ISBN: 9780470669952

Relational Suicide Assessment: Risks, Resources,

\& Possibilities for Safety

Douglas Flemons \& Leonard M. Gralnik

W. W. Norton \& Company, 2013, $£ 25.00$ hb, 272 pp.

ISBN: 9780393706529

The Intelligent Clinician's Guide to the DSM-5

Joel Paris

Oxford University Press, 2013, £18.99 pb, 288 pp.

ISBN: 9780199738175

Suicide Prevention (2nd edn)

Robert D. Goldney (ed.)

Oxford University Press, 2013, E19.99 pb, 120 pp.

ISBN: 9780199677580

doi: 10.1192/pb.bp.113.044834 